\title{
Omental and pleural milky spots: different reactivity patterns in mice infected with Schistosoma mansoni reveals coelomic compartmentalisation
}

\author{
Mônica S Panasco, Marcelo Pelajo-Machado, Henrique Leonel Lenzi/ ${ }^{+}$ \\ Laboratório de Patologia, Instituto Oswaldo Cruz-Fiocruz, Av. Brasil 4365, 21040-900 Rio de Janeiro, RJ, Brasil
}

\begin{abstract}
In vertebrate animals, pleural and peritoneal cavities are repositories of milky spots (MS), which constitute an organised coelom-associated lymphomyeloid tissue that is intensively activated by Schistosoma mansoni infection. This study compared the reactive patterns of peritoneal MS to pleural MS and concluded from histological analysis that they represent independent responsive compartments. Whole omentum, lungs and the entire mediastinum of $54 \mathrm{~S}$. mansoni-infected mice were studied morphologically. The omental MS of infected animals were highly activated, modulating from myeloid-lymphocytic (60 days of infection) to lymphomyeloid (90 days of infection) and lymphocytic or lymphoplasmacytic (160 days of infection) types. The non-lymphoid component predominated in the acute phase of infection and was expressed by monocytopoietic, eosinopoietic and neutropoietic foci, with isolated megakaryocytes and small foci of late normoblasts and mast cells. Nevertheless, pleural or thoracic MS of infected mice were monotonous, consisting of small and medium lymphocytes with few mast and plasma cells and no myeloid component. Our data indicate that compartmentalisation of the MS response is dependent on the lymphatic vascularisation of each coelomic cavity, limiting the effects or consequences of any stimulating or aggressive agents, as is the case with $\mathrm{S}$. mansoni infection.
\end{abstract}

Key words: Schistosoma mansoni - milky spot - omentum - pleura - thorax - coelom

The intraembryonic coelom in humans and vertebrate animals is divided into pericardial, pleural and peritoneal cavities. In these three cavities, especially in the omentum of the peritoneal cavity and in the pericardio-diaphragmatic membrane, there are milky spots (MS), which were originally described in young rabbits by Recklinghausen in 1863. MS of the human omentum were first pointed out by Seifert (1921). Hamazaki (1925) described MS in the omentum of the cat, dog, opossum and guinea pig. Maximow (1928) observed the presence of MS in the pleura of rabbit, guinea pig, rat, dog, cat and opossum in the region adjacent to the pericardium. Kampmeier (1928) discovered pleural MS in humans during the course of an investigation of the foetal thoracic duct. Mixter (1941) observed, with rare exceptions, that pleural MS are constant structures in all individuals beyond a certain period of development and growth among different mammals examined: rat, mouse, ground squirrel, rabbit, cat, dog, bat, mole and man. The function of MS has been discussed for many years (Beelen 1991, 1992, Koten \& den Otter 1991, Shimotsuma et al. 1992, Williams \& Davies 1992) and it is still a subject of debate. In ontogeny, MS appear in week 26 of foetal life, are well developed at birth and reach their maximum numbers around the first year of life, followed by an age-

+ Corresponding author: henrique.lenzi@gmail.com

Received 8 May 2009

Accepted 8 October 2009 related decline in number (Krist et al. 1997). They have also been suggested to be very reactive perivascular tissue involved in different aspects of B and T-cell functions and are regarded as omental-associated lymphoid tissue (Beelen 1991). Immunophenotyping and precursor cell kinetic studies demonstrated that MS play a role in the origin of peritoneal macrophages in rats (Wijffels et al. 1992) and that macrophages are the predominant cell type associated with these structures (Van Vugt et al. 1993), suggesting that MS are involved in peritoneal antibacterial defence (Liebermann-Meffert \& White 1983, Van Vugt et al. 1996). In our studies, we proposed that MS (individual structures), considered as a whole, constitute an organised coelom-associated lymphomyelopoietic tissue (CALT), which represents the main immune system in peritoneal and other coelomic cavities (Lenzi et al. 1996). More recently, we suggested that human and mouse MS are peculiar adipose-lymphomyeloid-mastocytic structures. Considering that schistosome adult worms live inside the mesenteric veins, which are connected with MS vasculature, their products can easily reach the MS, causing intense activation and transforming them into a bone marrow-like tissue that expresses all hematopoietic lineages (Lenzi et al. 1992, 1996, Weinberg et al. 1992).

In the present paper, we compared the reactive patterns of peritoneal MS to pleural MS and concluded, based on histological analysis, that they represent independent responsive compartments.

Fifty-four male Swiss Webster mice, bred in the animal house of the Department of Pathology, Instituto Oswaldo Cruz-Fiocruz, Rio de Janeiro, were percutaneously infected at five days of age with approximately 70 Schistosoma mansoni cercariae (BH strain), that had 

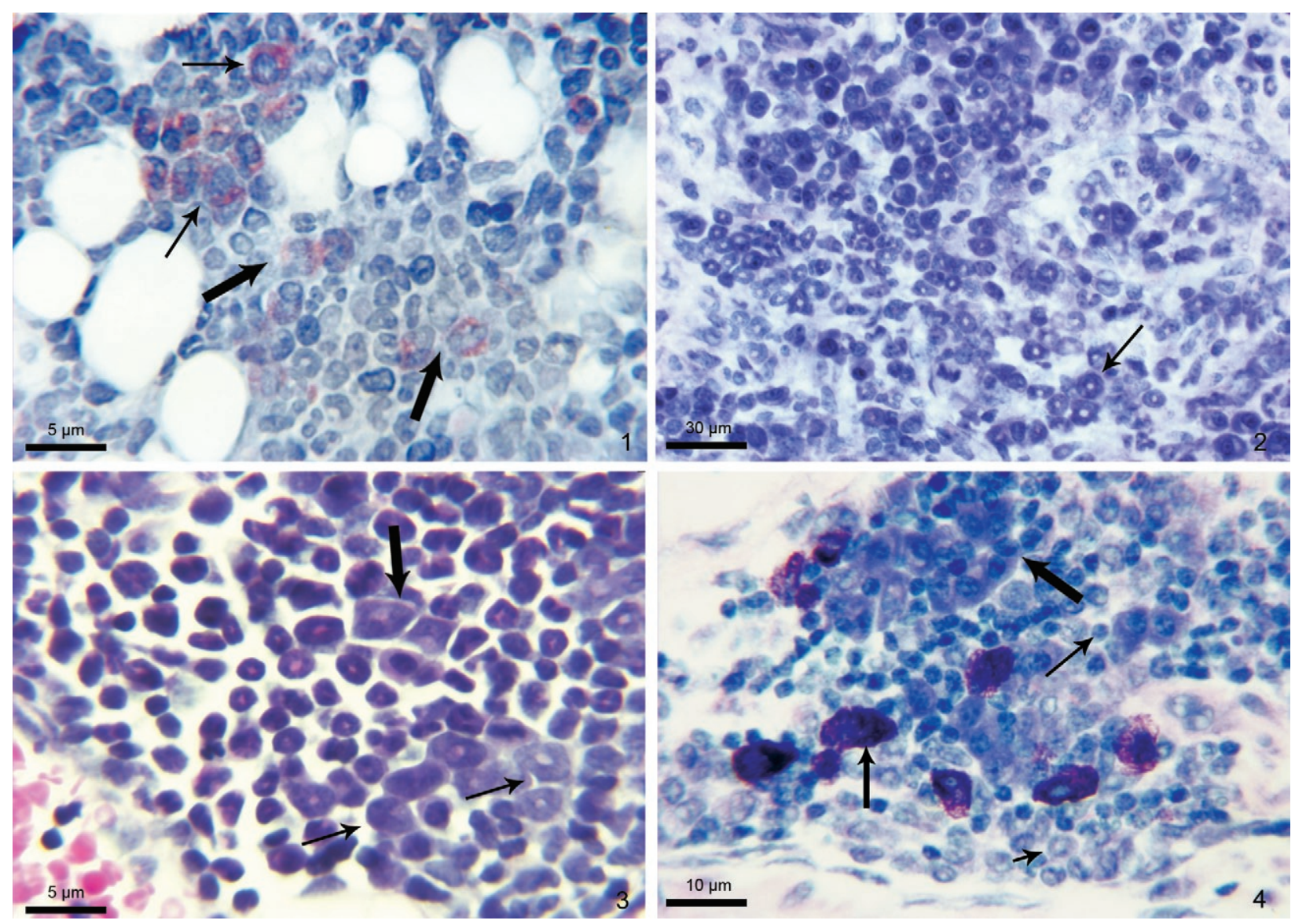

Fig. 1: omental milky spots with intense eosinopoiesis expressed by the presence of myelocytes (thin arrow) and metamyelocytes (thick arrow) (60 days of infection) (Sirius red pH 10.2); 2: prominent focus of neutropoiesis, consisting mainly of myelocytes and metamyelocytes (arrow) (60 days of infection) (Lennert's Giemsa); 3: adjacent foci of monocytopoiesis (thin arrow) and eosinopoiesis (thick arrow) (90 days of infection) (H\&E); 4: area with mast cells (thin arrow), plasma cells forming a cluster (thick arrow), small lymphocytes and neutrophils (short arrow) (90 days of infection) (Lennert's Giemsa).

been maintained in Biomphalaria glabrata snails. The mice were submitted to euthanasia by ether inhalation (in accordance with animal ethical practices) to take omental, mesenteric and pleural membrane samples at 60, 90 and 160 days after infection (18 animals/group). Eighteen age-matched, non-infected animals were used as controls (6 animals/group).

Whole omentum, lungs and the entire mediastinum of each animal were fixed in Carson's modified Millonig's phosphate-buffered formalin, $\mathrm{pH} 7.4$ (Carson's formalin Millonig) (Carson et al. 1973) for $48 \mathrm{~h}$, with one change of the fixative at $24 \mathrm{~h}$. Afterward, the samples were embedded in paraffin and histological sections (5 $\mu \mathrm{m})$ were stained with Hematoxylin-Eosin, Lennert's Giemsa (Lennert 1978), Gomori's reticulin, Masson's trichrome, Weigert's resorcin-fucsin, PAS-Alcian Blue (pH 1.0 and 2.5) and Picrosirius red (with/without polarisation) (Junqueira et al. 1979), Alcian-Blue safranin (Strobel et al. 1981) and Sirius red (pH 10.2) (Bogomoletz 1980, Luque \& Montes 1989). Sections stained with phosphomolybdic acid-picrosirius red (Dolber \& Spach 1993) were analysed by confocal laser scanning microscopy (Zeiss LSM-410).
Omental MS of infected animals were highly activated in all periods of infection studied. According to the presence of cells, they modulated from myelolymphocytic (60 days of infection) to lymphomyeloid (90 days of infection) and lymphocytic or lymphoplasmacytic (160 days of infection) types. The non-lymphoid component predominated in the acute phase of infection and was expressed by a variable number and intensity of monocytopoietic, eosinopoietic and neutropoietic foci, with sparse megakaryocytes and small foci of late normoblasts (Figs 1-3, 6).

With the progression of the infection, the myeloid component decreased in intensity and the lymphocytes and plasma cells became more numerous. Lymphocytes were predominantly of small or medium size; among them, we could distinguish immunoblasts that were mainly in the acute phase. Occasionally, some lymphocytes acquired a monocytoid aspect, but formation of germinal centres was infrequent. Plasma cells were frequent and appeared in isolated groups or dispersed with lymphocytes, eosinophils and other cells (Figs 4, 5).

Mast cells varied in number from MS to MS and were often associated with mesothelial cells (Fig. 4). In 

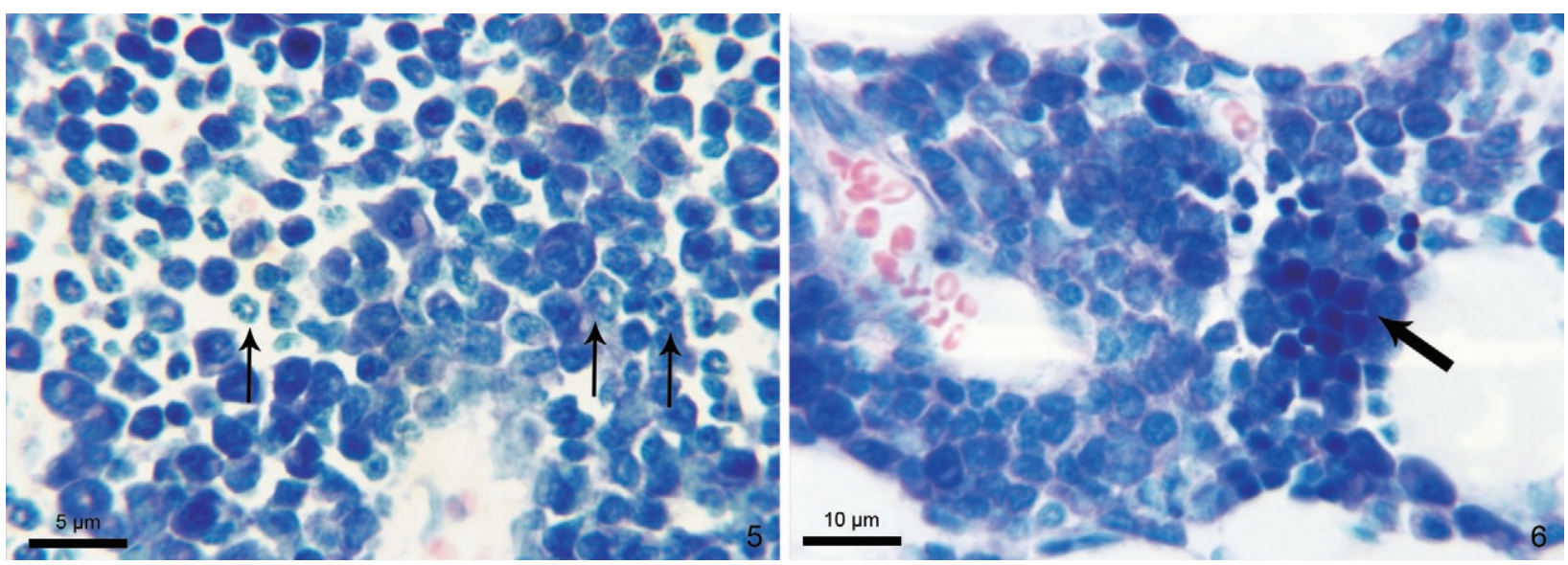

Fig. 5: perivascular plasma cells and neutrophils (arrows) (90 days of infection) (Lennert's Giemsa); 6: small focus of late normoblasts (arrow) (160 days of infection) (Lennert's Giemsa).

cellular MS, these were hypertrophic (type II mesothelial cells) and positive to low sulphated proteoglycans and/or hyaluronic acid.

During all periods of infection, the stroma consisted of fat cells and fibroblastic-like cells in different proportions, intermixed in a mesh of reticular and collagenic fibres and few elastic fibres restricted to vascular walls and under the mesothelial lining.

Periovular granulomas, predominantly of exudativeproductive type, were frequently detected. In control mice, MS were mainly lymphomonocytic, predominantly medium lymphocytes with occasional monocytoid or centrocytic-like aspects (Fig. 7). As in infected mice, lymphocytes formed perivascular sheaths or pseudofollicles. Activated lymphocytes were also present and were expressed by lymphoblastic-like cells, immunoblasts and a few plasma cells, including Mott cells, especially in the interface with the adipose tissue; they were always fewer in number than in infected mice. Monocytes and macrophages were frequently detected, but myeloid populations were not seen or were only represented by some mature eosinophils and rare eosinopoietic foci and neutrophils. Mast cells were scarce and isolated megakaryocytes were only occasionally observed.

Pleural or thoracic MS of infected mice were monotonous, consisting of small and medium lymphocytes with few mast and plasma cells. The myeloid component was absent during all periods of infection, similar to the MS of control mice (Figs 8-10).

The expressive differential reactivity between omental and pleural MS in S. mansoni-infected mice indicates that coelomic cavities act as independent environments. This compartmentalisation of the MS response to schistosomal infection appears to be a paradoxical event, considering that the infection disperses eggs and parasitic soluble products to extraintestinal organs (mainly the liver), provoking systemic reactions with intense bone-marrow involvement (Lenzi et al. 1987, 1995). This paradox is intensified by the presence of anatomical contact between the peritoneal cavity and subpleural lymphatics through the stomata and intercellular gaps between endothelia and mesothelial cells, which allow peritoneal fluid to pass through the diaphragm and enter the pleural cavity (Ohtani et al. 1995). Intraperitoneal injection of India ink in rats was shown to enter the subperitoneal lymphatics through lymphatic stomata and to drain through the subpleural collecting lymphatics into the parasternal, paravertebral and mediastinal lymphatic trunks, as well as the thoracic duct (Ohtani \& Ohtani 1997). The lymph vessels of the parietal pleura form fine networks in the subpleural region and flow into the collecting vessels of the intercostal spaces. There are one or two collecting vessels for each space (Nagaishi 1972). The lymph flow from parietal pleura flows in different directions, according to the region of origin. The lymph originating in the regions anterior to the anterior axillary line flows anteriorly via the anterior intercostals lymph nodes, internal mammary nodes and substernal nodes into the venous angle. The lymph originating in the region posterior to the axillary line flows posteriorly via the posterior intercostals and prevertebral lymph nodes into the thoracic duct and then into the venous angle (Nagaishi 1972). There is not likely to be any communication of these networks of lymphatic vessels with the pleural and omental MS lymphatic vessels. In fact, each individual MS operates as a source of correspondent efferent lymphatic vessel that drains lymph and cells to upstream main lymphatic routes, which discharge into the thoracic duct, explaining the apparent paradox between systemic and local (coelomatic) reactivity in schistosomiasis.

The presence of periovular granulomas inside MS is indicative that eggs and other schistosome products can reach them through reverse (upstream) venous circulation.

Pleura MS seem to be related to pleural cavities rather than to lung parenchyma. When we injected schistosomal eggs into the caudal vein of mice, the eggs were carried out to the lungs, causing a periovular granulomatous reaction without MS mobilisation. When eggs were injected into the pleural cavities, MS cells increased in number (unpublished observations). 

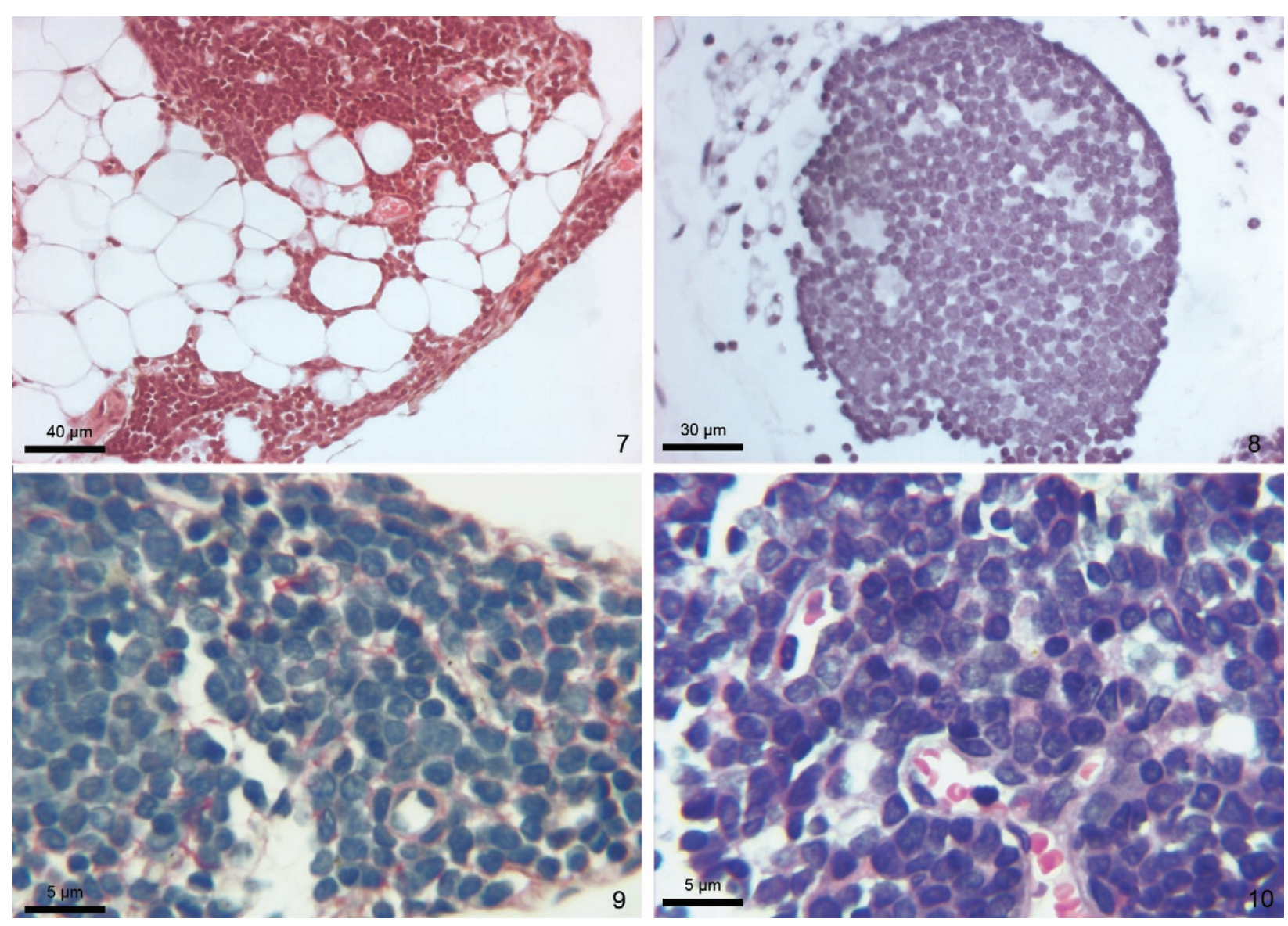

Fig. 7: panoramic view of control mouse omentum presenting two little milky spots consisting of small lymphocytes (65 days of life) (H\&E); 8-10: three pleural milky spots, showing a monotonous lymphocytic aspect, without evidence of myeloid lineages (60 days of infection) (Figs 8, 10: H\&E; Fig. 9: Picrosirius).

The compartmentalisation of MS in each coelomic cavity appears to be a consequence of the segmentation that operates as an early key innovation in body plan that emerged among the coelomates (Raven \& Johnson 1996). Because partitions separated the segments, it was necessary to provide ways for material to pass between them. Thus, a circulatory system carried blood from one segment to another (Raven \& Johnson 1996). If not, each coelomic cavity would maintain its primordial immune system independently. CALT, which is made up of MS, is likely to be ontogenetically derived from splanchnopleura [intraembryonic aorta (dorsal), genital ridge and mesonephros] (Dzierzak \& Medvinsky 1995) and represents a primordial organ that maintains the "phylogenetic memory" of the coelomassociated lymphomyeloid organs (Lenzi et al. 1998).

During schistosome infection, there is morphological evidence of involvement of various hematopoietic growth factors, which act in different sites, especially around hepatic granulomas, in lymph nodes and in MS, causing extramedullary haematopoiesis (Lenzi et al. 1995). The haematopoietic foci appeared to be locally regulated; concerning MS, it is still unknown whether progenitor cells are originated in situ or are derived from bone marrow. We detected a large number of
c-Kit positive cells in omental MS from both control and infected mice, while other immature markers (Fall-3, Sca-1) were negative (data not shown).

The functional consequences of omental and mesenteric MS stimulation by $S$. mansoni are unknown, although some hypotheses were discussed in Lenzi et al. (1992, 1996, 1997) and Weinberg et al. (1992).

The compartmentalisation of the MS response is dependent on the characteristics of lymphatic vascularisation of each coelomic cavity, which spatially limits, as a secondary outcome, the effects or consequences of any stimulating or aggressive agents, as in the case of $S$. mansoni infection.

\section{REFERENCES}

Beelen RH 1991. The greater omentum: physiology and immunological concepts. Neth J Surg 43: 145-149.

Beelen RH 1992. Role of omental milky spots in the local immune response. Lancet 339: 689.

Bogomoletz W 1980. Avantages de la coloration par le rouge Sirius de l'amyloïde et des éosinophiles. Arch Anat Cytol Pathol 28: 252-253.

Carson FL, Martin JH, Lynn JA 1973. Formalin fixation for electron microscopy: a re-evaluation. Am J Clin Pathol 59: 365-373. 
Dolber PC, Spach MS 1993. Conventional and confocal fluorescence microscopy of collagen fibers in the heart. J Histochem Cytochem 41: 465-469.

Dzierzak E, Medvinsky A 1995. Mouse embryonic hematopoiesis. Trends Genet 11: 359-366.

Hamazaki Y 1925. Comparative studies on the milky spots, "taches laiteuses", of various animals. Folia Anatomica Japonica 3: 243-265.

Junqueira LC, Bignolas G, Brentani RR 1979. Picrosirius staining plus polarization microscopy, a specific method for collagen detection in tissue sections. Histochem J 11: 447-455.

Kampmeier OF 1928. Concerning certain mesothelial thickenings and vascular plexuses of the mediastinal pleura, associated with histiocyte and fat-cell production, in the human newborn. Anat $\operatorname{Rec}$ 39: 201-208.

Koten JW, den Otter W 1991. Are omental milky spots an intestinal thymus? Lancet 338: 1189-1190.

Krist LFG, Koenen JPM, Meijer S, Beelen RHJ 1997. Ontogenic development of human milky spots. Anat Rec 249: 399-404.

Lennert K 1978. Malignant lymphomas other than Hodgkin's disease, Springer-Verlag, Berlin, 833 pp.

Lenzi HL, Lenzi JA, Rosman FC, Pelajo-Machado M, Mota EM, Panasco MS, Oliveira DN 1995. Extramedullary hematopoiesis in murine schistosomiasis mansoni. Mem Inst Oswaldo Cruz 90: 169-177.

Lenzi HL, Oliveira DN, Borojevic R, Lenzi JA 1992. Milky spots reaction to schistosomal mansoni infection. Mem Inst Oswaldo Cruz 87 (Suppl. V): 111-116.

Lenzi HL, Oliveira DN, Pelajo-Machado M, Borojevic R, Lenzi JA 1996. Coelom-associated lymphomyeloid tissue (milky spots): site of lymphoid and myelomonocytic cell generation. Braz J Med Biol Res 29: 19-24.

Lenzi HL, Pacheco RG, Pelajo-Machado M, Panasco MS, Romanha WS, Lenzi JA 1997. Immunological system and Schistosoma mansoni: co-evolutionary immunobiology. What is the eosinophil role in parasite-host relationship? Mem Inst Oswaldo Cruz 92 (Suppl. II): 19-32.

Lenzi HL, Sobral AC, Lenzi JA 1987. "In vivo" kinetics of eosinophils and mast cells in experimental murine schistosomiasis. Mem Inst Oswaldo Cruz 82 (Suppl. IV): 67-76.

Lenzi JA, Pelajo-Machado M, Mota EM, Oliveira DN, Panasco MS, Andrade ZA, Lenzi HL 1998. Effects of schistosomal mansoni infection on Calomys callosus coelom-associated lymphomyeloid tissue (milky spots). Mem Inst Oswaldo Cruz 93 (Suppl. I): 13-23.

Liebermann-Meffert D, White H 1983. The greater omentum: anato$m y$, physiology, pathology and surgery, with an historical survey, Springer-Verlag, Berlin, $361 \mathrm{pp}$.
Luque EH, Montes GS 1989. Progesterone promotes a massive infiltration of the rat uterine cervix by the eosinophilic polymorphonuclear leukocytes. Anat Rec 223: 257-265.

Maximow A 1928. Bindegewebe und blutbildende gewebe. In H von W Mollendorff, Handbuch der mikroskopischen anatomie des menschen, Springer-Verlag, Berlin, p. 238.

Mixter RL 1941. On macrophagal foci (milky spots) in the pleura of different mammals, including man. Am J Anat 69: 159-186.

Nagaishi C 1972. Functional anatomy and histology of the lung, Igaku Shoin Ltd, Tokyo, 295 pp.

Ohtani Y, Ohtani O 1997. Obliteration of the lymphatic trunks draining diaphragmatic lymph causes peritoneal fluid to enter the pleural cavity. Arch Histol Cytol 60: 503-510.

Ohtani Y, Ohtani O, Nakatani T 1995. Microanatomy of the rat diaphragm with special reference to the lymphatics and mesothelial stomata. Ital J Anat Embryol 100 (Suppl. 1): 143-153.

Raven PH, Johnson GB 1996. Biology, 4th ed., Wm C Brown Publishers, Dubuque, 1310 pp.

Recklinghausen F Von 1863. Uber eiter und bindesgewebsKörperchen. Virchows Arch Pathol Anat 28: 157-166.

Seifert E 1921. Zur biologie des menschlichen grossen netzes. Arch Klin Chir 116: 510-517.

Shimotsuma M, Shirasu M, Hagiwara A, Takahashi T, Shields JW 1992. Omental milky spots and the local immune response. Lancet 339: 1232.

Strobel S, Miller HR, Ferguson A 1981. Human intestinal mucosal mast cells: evaluation of fixation and staining techniques. $J$ Clin Pathol 34: 851-858.

Van Vugt E, Kamperdijk EWA, Beelen RHJ 1993. A congeneic rat model to study migration in vivo. Transplant Proc 25: 2808-2810.

Van Vugt E, Van Rijthoven EA, Kamperdijk EW, Beelen RH 1996. Omental milky spots in the local immune response in the peritoneal cavity of rats. Anat Rec 244: 235-245.

Weinberg DF, Baldo-Correa E, Lenzi HL, Borojevic R 1992. Schistosoma mansoni: peritoneal plasmacytogenesis and polypoid transformation of mesenteric milky spots in infected mice. Exp Parasitol 74: 408-416.

Wijffels JF, Hendrickx RJ, Steenbergen JJ, Eestermans IL, Beelen RH 1992. Milky spots in the mouse omentum may play an important role in the origin of peritoneal macrophages. Res Immunol 143: 401-409.

Williams RJ, Davies AJ 1992. Omental milky spots. Lancet 339: 191-192. 